\title{
The comparative gastrointestinal morphology of five species of muroid rodents found in Saudi Arabia
}

\author{
Jacklynn Walters, ${ }^{1}$ Sumine Marais, ${ }^{1}$ Olga Johnson, ${ }^{1}$ Nigel C. Bennett, ${ }^{2}$ Abdulaziz \\ N. Alagaili, ${ }^{3,4}$ Osama B. Mohammed ${ }^{3}$, Sanet H. Kotzé, ${ }^{1 *}$ \\ ${ }^{1}$ Division of Anatomy and Histology, Department of Biomedical Sciences, Stellenbosch University, \\ Tygerberg, 7505, South Africa, \\ ${ }^{2}$ Department of Zoology and Entomology, Mammal Research Institute, University of Pretoria, Pretoria, \\ 0002, South Africa, \\ ${ }^{3}$ KSU Mammals Research Chair, Department of Zoology, College of Science, King Saud University, \\ Riyadh, 11451, Saudi Arabia. \\ ${ }^{4}$ Saudi Wildlife Authority, P.O. Box 61681, Riyadh 11575, Saudi Arabia. \\ *Correspondence to: Sanet Kotze', Department of Biomedical Sciences, Faculty of Medicine and Health \\ Sciences, University of Stellenbosch, Tygerberg 7505, South Africa. \\ E-mail: $\underline{\text { shk@sun.ac.za }}$
}

\begin{abstract}
Meriones rex (King jird), Meriones libycus (Libyan jird), Acomys dimidiatus (Eastern spiny mouse), Acomys cahirinus (Egyptian spiny mouse) and Dipodillus dasyurus (Wagner's dipodil) are five species of small rodents of the superfamily Muroidea with distributions in Eastern Africa, Egypt and the desert regions of the Arabian Peninsula. Water is scarce in these regions and may result in relatively low-digestible food. The aim of the present study is to describe and compare the gastrointestinal tract (GIT) morphology and morphometry of these five species in order to elucidate whether morphology is influenced by phylogeny or dietary preference.
\end{abstract}


Each GIT segment of each species was macroscopically examined and the length and basal surface area of each segment was measured. Standard histologic procedures were performed to determine a surface enlargement factor to determine the mucosal luminal surface area.

A unilocular-hemiglandular stomach was observed in all the species examined. The caeca of all the species were long and arranged into a loose spiral towards the caecal tip with the ileocaecal and caeco-colic openings positioned close together. Two rows of oblique folds could be observed in the proximal colon of all species except in $D$. dasyurus which had longitudinal folds. Morphometric analysis showed the largest stomach in A. cahirinus and the largest caecum and colon in M. libycus.

All the species can be grouped in the family Muridae in two subfamilies and similarities were observed including the hemiglandular stomach and relatively large caecum. It could be concluded that phylogeny plays an important role in determining GIT morphology while diet plays a subordinate role in the desert rodents in the present study.

\section{Introduction}

Meriones rex (King jird), Meriones libycus (Libyan jird), Acomys dimidiatus (Eastern spiny mouse), Acomys cahirinus (Egyptian spiny mouse) and Dipodillus dasyurus (Wagner's dipodil) are five species of small rodents of the superfamily Muroidea distributed in Eastern Africa, Egypt and the desert regions of the Arabian Peninsula with $M$. rex almost exclusively found in the south western corner of the Arabian Peninsula (Harrison \& Bates, 1991). These species represent two subfamilies namely 
Deomyinae (Acomys species) and Gerbillinae (Meriones and Dipodillus) (Musser and Carleton, 2005).

Desert dwelling rodents living in conditions where water is scarce, often develop mechanisms to preserve energy such as lower resting metabolic rates (RER) and lower absolute energy demands than rodents of the same size living in environments with higher energy food sources (Scantlebury et al., 2005). Other adaptations such as hibernation and nocturnal activity described in some desert species may also preserve energy. While Vesey-Fitzgerald (1966) and Alagaili et al., (2012a) described $D$. dasyurus as nocturnal, the Meriones species were reported to be diurnal (Sanborn and Hoogstraal, 1953; Nowak and Paradiso, 1983). However, in a recent study conducted by Alagaili et al., (2012b) both $M$. rex and M. libycus were found to be nocturnal under laboratory conditions. A. cahirinus was found to be mainly nocturnal (Nowak and Paradiso, 1983) and reduced urine production in this species enables it to be very resilient in extreme dry conditions (Harrison and Bates, 1991). A. dimidiatus exhibited nocturnal activity under laboratory conditions (Alagaili et al., 2013).

Of the five species introduced in the present study, the two Meriones species and Dipodillus dasyurus are reported in the literature to only consume vegetation including plant material and seeds (Harrison and Bates, 1991; Nowak and Paradiso, 1983) while the two Acomys species have been described to ingest small amounts of invertebrates in addition to mainly plant material, putting them in the category of omnivores (Varty, 1990; Harrison and Bates, 1991). There is paucity in the literature about the gastrointestinal tract (GIT) morphology of these rodent species occurring in the Arabian Peninsula. We postulate that the GIT of desert dwelling species may be adapted to 
conditions where water is scarce and consequently relatively low-digestible food. The aim of the present study is to describe and compare the GIT morphology and morphometry of five species of small rodents in order to elucidate whether morphology is influenced by phylogeny or dietary preferences.

\section{Material and Methods}

Intact, fixed gastrointestinal tract (GIT) specimens were obtained from animals that were euthanized and perfusion fixed with paraformaldehyde (PFA), where parts of the fixed animals were used for an unrelated study. The animals were captured in the wild from south-western and central Saudi Arabia with permission from the Saudi Wildlife Authority (SWA). M rex, A. dimidiatus, and D. dasyurus were captured in the Raydah Protected Area near Abha city in south Saudi Arabia. A. cahirinus and some A. dimidiatus were from the National Wildlife Research Centre, Taif. M. libycus were captured in two locations: Unizah and Riyadh. Ethical clearance was obtained from the University of Pretoria (UP) and Stellenbosch University (US). Animals were weighed before the abdominal tracts were removed from the distal part of the oesophagus to the distal colon as far as could be reached into the pelvic cavity. Before any measurements of the GIT were taken, each GIT was examined, photographed and weighed. All species used in this study were identified using genetic profiling and blasting against sequences on GenBank (www.ncbi.nlm.nih.gov). Information about the species used is listed in table 1 . 
Table 1: List of the species used, including the common names, sample size, and mean gastrointestinal weights, body weights and proportional GIT weights ( \pm Std. Dev.)

\begin{tabular}{|c|c|c|c|c|c|}
\hline Species & Common name & $n$ & Mean BW (g) & $\begin{array}{l}\text { Mean GIT } \\
\text { weight (g) }\end{array}$ & $\begin{array}{l}\text { Proportional } \\
\text { GIT weight to } \\
\text { Total BW }(\%)\end{array}$ \\
\hline Meriones rex & King jird & 5 & $\begin{array}{l}122.80 \\
( \pm 15.69)\end{array}$ & $18.53( \pm 6.73)$ & $14.83( \pm 4.36)$ \\
\hline Meriones libycus & Libyan jird & 5 & $80.80( \pm 35.51)$ & $14.90( \pm 7.18)$ & $19.72( \pm 7.18)$ \\
\hline Acomys dimidiatus & Eastern spiny mouse & 5 & $34.20( \pm 7.85)$ & $6.11( \pm 2.38)$ & $18.56( \pm 8.36)$ \\
\hline Acomys cahirinus & $\begin{array}{l}\text { Egyptian } \\
\text { mouse }\end{array}$ & 4 & $38.00( \pm 7.07)$ & $6.17( \pm 1.57)$ & $16.08( \pm 1.77)$ \\
\hline $\begin{array}{l}\text { Dipodillus } \\
\text { dasyurus }\end{array}$ & Wagner's Dipodil & 3 & $33.00( \pm 9.85)$ & $5.79( \pm 3.01)$ & $16.83( \pm 5.52)$ \\
\hline
\end{tabular}

The length of each of the anatomically distinct parts of the GIT (stomach, small intestine, caecum, and colon) was measured on the anti-mesenteric border using a pliable, non-stretchable cord. The length for each part was then expressed as a proportion of the total GIT length. The length of the stomach was measured along the greater curvature from the tip of the fundus to the end of the pyloric region. The small intestine length was measured from the start of the duodenum just distal to the pylorus to the ileocaecal junction. The length of the caecum was measured from the distal tip of the caecum to the caeco-colic junction on the antemesenteric border while the colon was measured from the caeco-colic junction to the rectum.

The mean circumferences of each anatomically distinct part were calculated by measuring the circumference at three levels. The basal surface area (BSA) was calculated by multiplying the mean circumference with the length of the part. After all the measurements were completed, the GITs were opened and the internal surfaces examined and photographed. All measurements were carried out in the same way in all the species studied. 
After all photographs were taken and all measurements completed, histologic samples were taken from each species from the corpus and fundus of the stomach, proximal, middle and distal small intestine, caecum, and proximal and distal colon. Samples were routinely processed for histology, serial sections cut at $5 \mu \mathrm{m}$ and stained with Haematoxylin and Eosin (H\&E).

In order to take into account the effect of mucosal villi and folds on measurements, the luminal surface area (LSA) was calculated by determining a surface enlargement factor for each of the anatomically distinct segments of the GIT. This was done by measuring the epithelial surface length on a cross section of a particular part as well as the outer serosal surface for that same field of view using the imaging software NIS Elements Basic Research (BR) (Version 3.10). Measurements were performed on three or more fields of view for each tissue section. Dividing the epithelium surface length by the outer surface length provided a factor representing the change in surface area due to folds and villi. This factor was called the surface enlargement factor and was determined separately for each anatomically distinct region. The surface enlargement factor was then multiplied with the BSA of each region in order to determine the LSA.

A sample of stomach content from each animal was prepared for histology and stained using H\&E to evaluate diet. The slides were examined under a Zeiss Axioxskop2 light microscope with a digital camera. The surface area of all recognizable material observed on the slides was measured in $\mu \mathrm{m}^{2}$. Digested material which was unidentifiable under the light microscope was not measured. Measured tissue was classified as plant, seed, or insect material. The sum of the surface area of each type of 
tissue on a slide was calculated and given as a percentage of the total sum of the measured surface areas on that slide.

For statistical analysis of the various measurements, Microsoft Excel (2007) was used to organize the data after which Statistica software was used to perform the statistical analysis. Normal probability plots were drawn to determine if the data is normally distributed. Descriptive statistics were completed to determine the mean values of the variables as well as their standard deviations and standard errors. An analysis of variance (ANOVA) was performed in order to determine statistically significant differences. Lavene's Test for Homogeneity of Variances was performed to verify this assumption. Fisher's Least Significant Difference (LSD) test was used to calculate the p-values. A p-value $<0.05$ was taken as statistically significant. Both Pearson and Spearman correlations were performed between the length, BSA and LSA of each region and the body weight.

\section{Results}

\section{Descriptive anatomy}

The stomach of each species was bean shaped with a sharp angular incision. Thus the oesophageal entrance and cardiac region was closely situated to the pyloric region. Both the Acomys species (Fig. 1C \& D) had a curved fornix while D. dasyurus (Fig. 1E) had a particularly pronounced fornix. In all the species the fornix extended beyond the oesophageal opening and was prominent. 


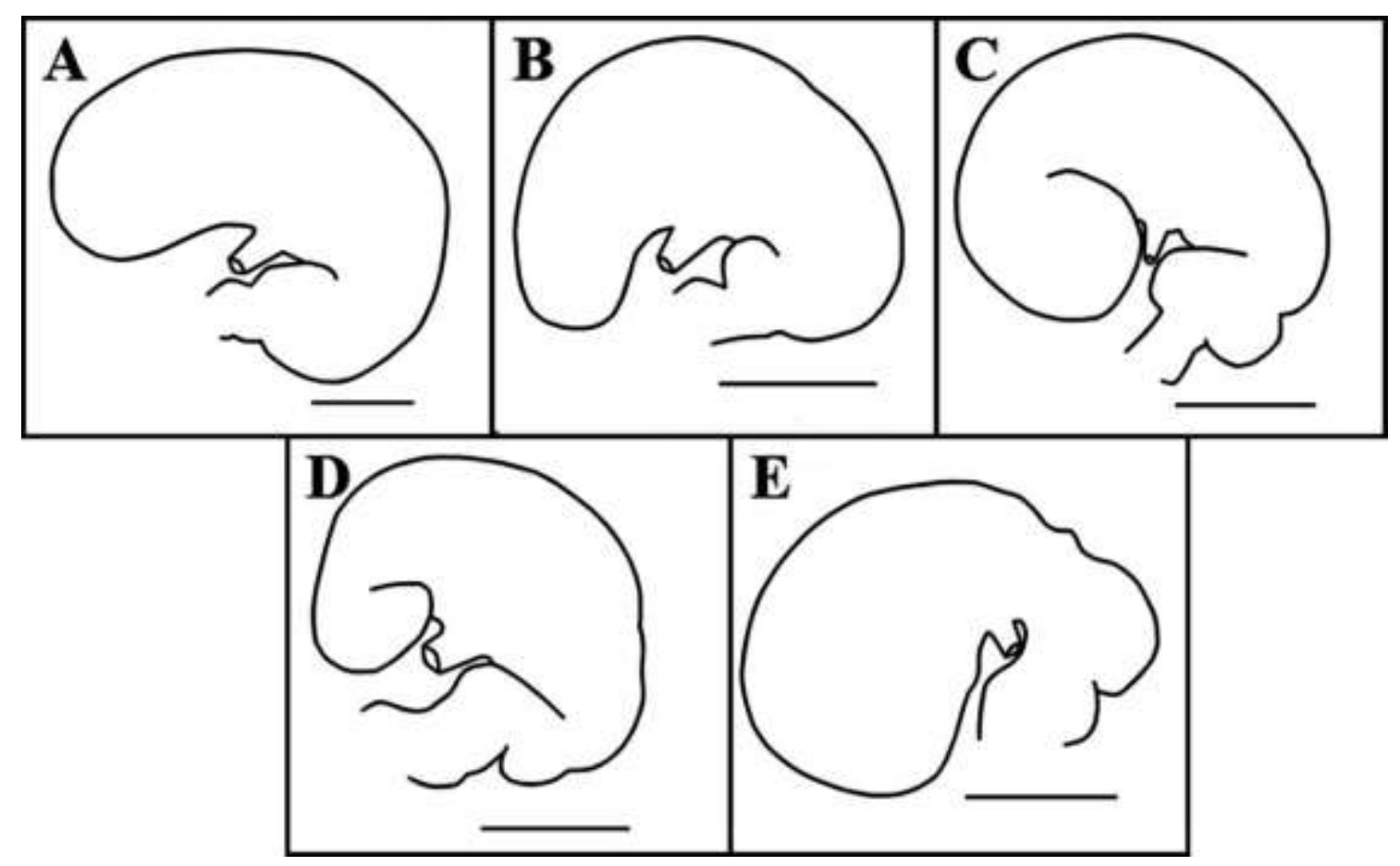

Fig. 1. Line diagrams of the outer stomach. A comparison of the stomachs of A) Meriones rex; B) Meriones libycus; C) Acomys dimidiatus; D) Acomys cahirinus; E) Dipodillus dasyurus. Bar $=1 \mathrm{~cm}$

All the species studied had a unilocular-hemiglandular stomach which consisted of a macroscopically visible non-glandular area and a glandular area separated by a bordering fold or limiting ridge. The bordering fold stretched from the angular incisure of the lesser curvature to the greater curvature opposite the angular incisure in all species. Histologic examination confirmed the presence of non-glandular stratified squamous epithelium proximal to the bordering fold while the mucosa distal to the fold consisted of glandular epithelium (Fig. 2). 


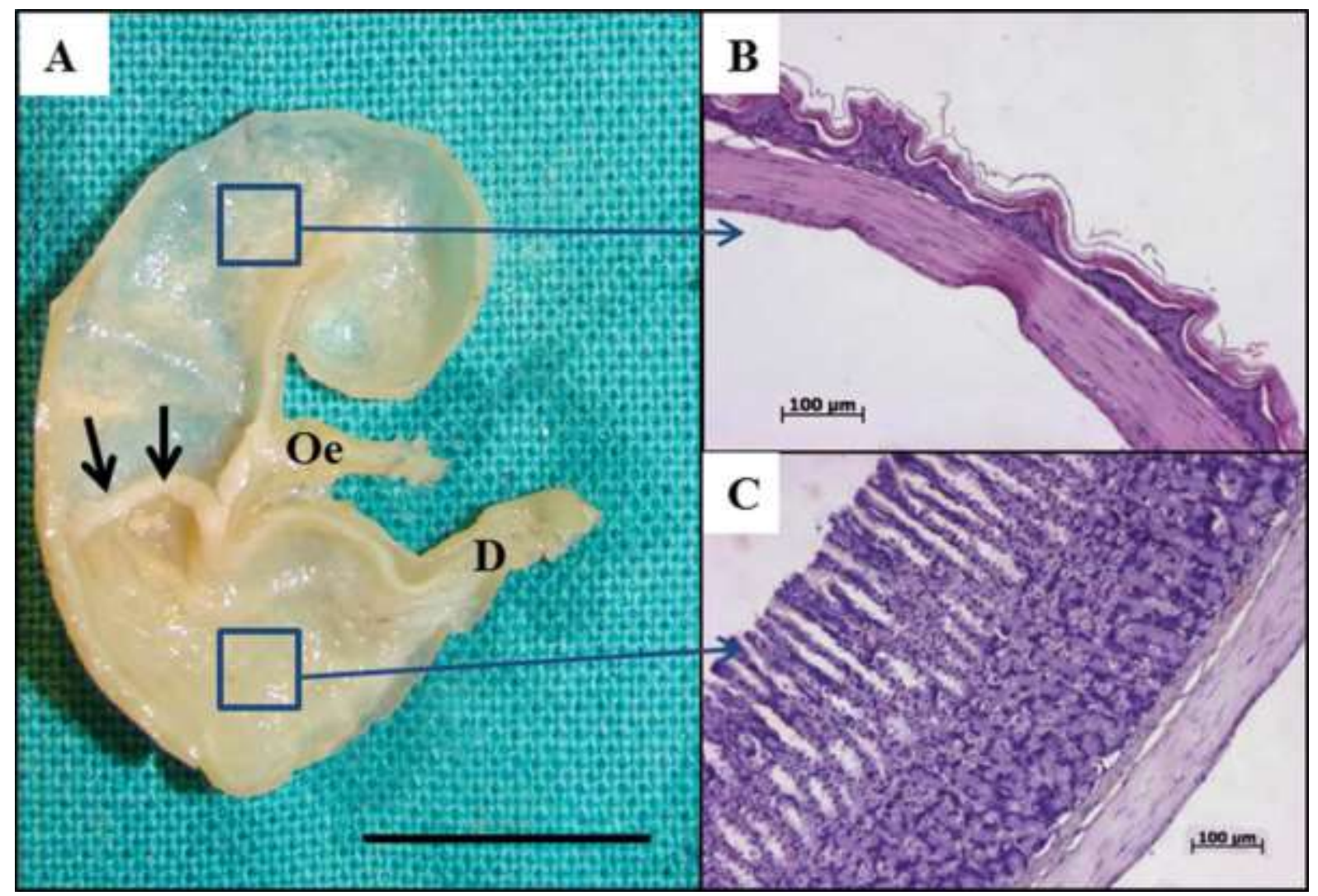

Fig. 2. Morphology of the mucosal surface stomach of $A$. dimidiatus as an example of the hemiglandular stomach morphology observed in all species examined. A) Macroscopic appearance of the inner stomach with arrows indicating the macroscopically visible bordering fold. Oe = Oesophagus. $\mathrm{D}=$ Duodenum. Bar $=1 \mathrm{~cm} \mathrm{~B}$ ) Stratified squamous epithelium of the stomach proximal to the bordering fold. $\mathrm{Bar}=100 \mu \mathrm{m} ; \mathrm{C}$ ) Glandular epithelium of the stomach distal to the bordering fold. Bar $=100 \mu \mathrm{m}$.

The caeca of all the species were elongated and arranged into a loose spiral towards the caecal tip (Fig. 3). All species had caeca with the ileocaecal and caeco-colic openings were positioned close together. Discreet haustra were observed on the antemesenterial border in the caecum of the two Meriones species. 


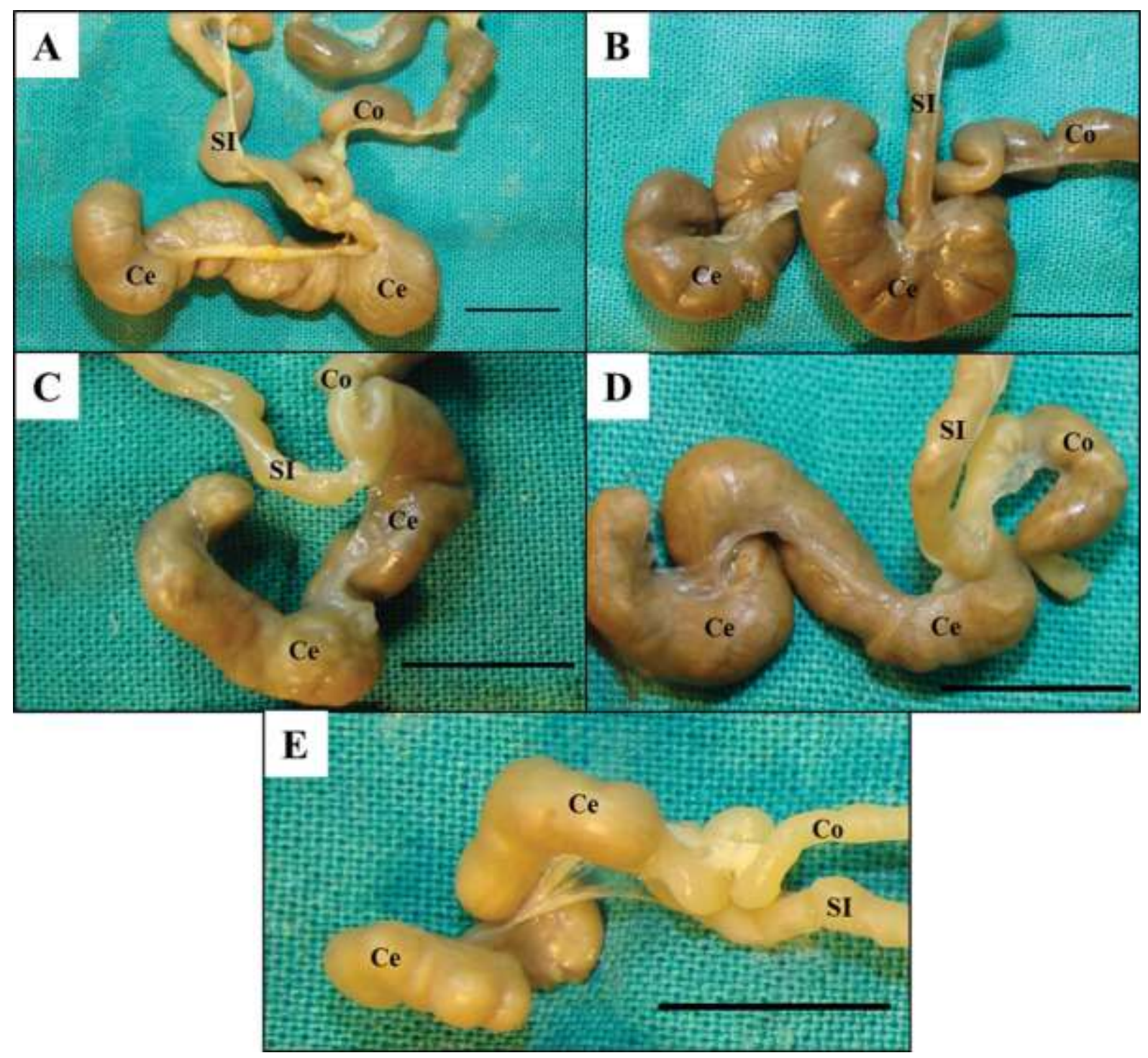

Fig. 3. Comparison of the caeca of A) M. rex; B) M. libycus; C) A. dimidiatus; D) A. cahirinus; E) D. dasyurus; $\mathrm{Ce}=$ Caecum. $\mathrm{Co}=$ Proximal colon. $\mathrm{SI}=$ Small intestine. $\mathrm{Bar}=1 \mathrm{~cm}$.

In all species examined the colon was arranged in a loop with the two limbs of the loop attached to each other by a short mesenterial fold (Fig. 4). Mucosal folds which were arranged in two longitudinal rows of oblique folds, could be observed in all species except in D. dasyurus where the folds were $\mathrm{V}$ shaped proximally but were arranged in a longitudinally directed loose spiral distally (Fig. 5). In all species the folds were observable from the outer serosal aspect and could be confirmed histologically (Fig. 5). 


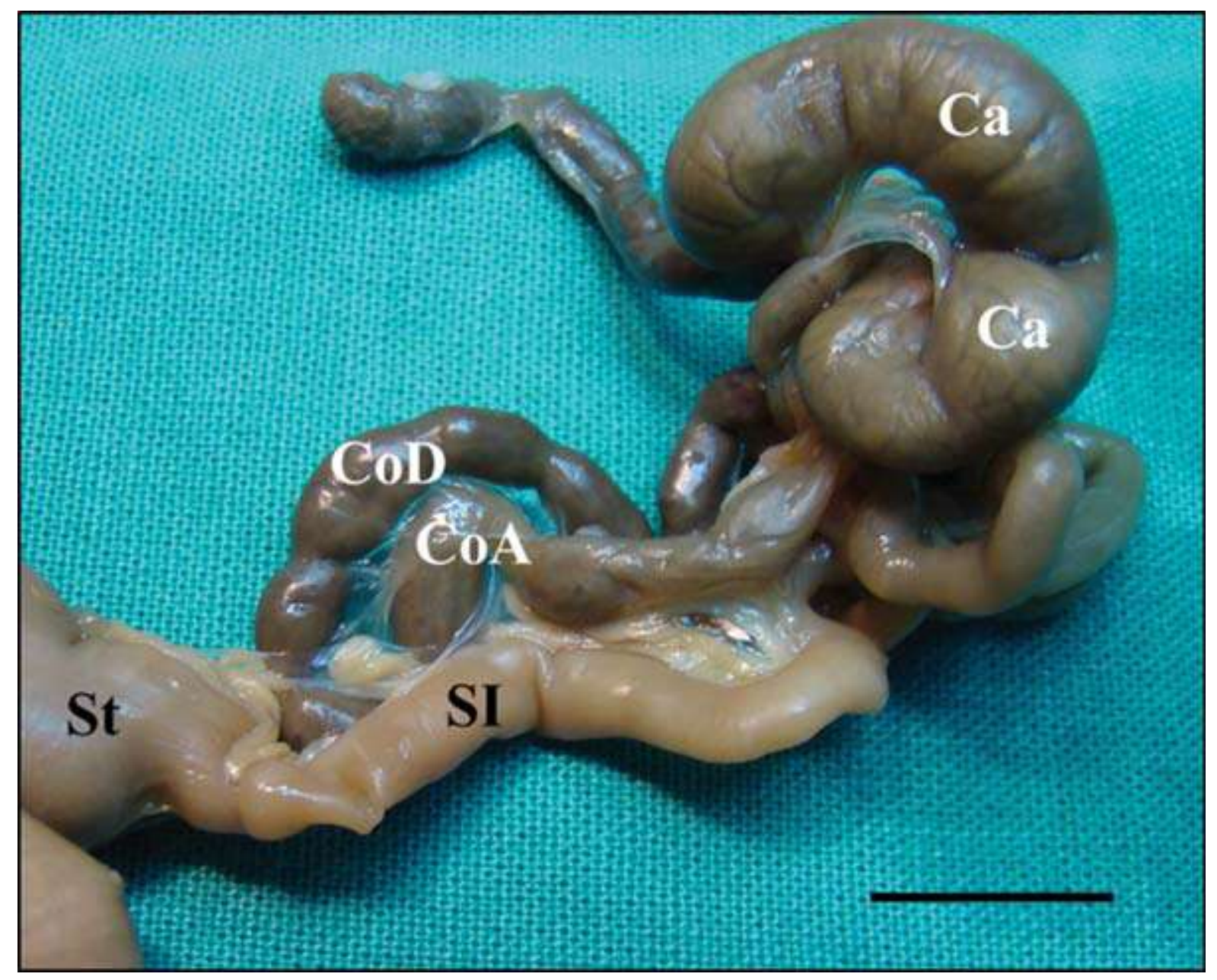

Fig. 4. Colon loop of $A$. dimidiatus. $\mathrm{Ca}=\mathrm{Caecum} . \mathrm{CoA}=$ Ascending (proximal) limb of the colon loop.

$\mathrm{CoD}=$ Descending $($ distal $)$ limb of the colon loop. $\mathrm{D}=$ Distal colon. $\mathrm{SI}=$ Small intestine. St $=$ Stomach . Bar $=1 \mathrm{~cm}$. 


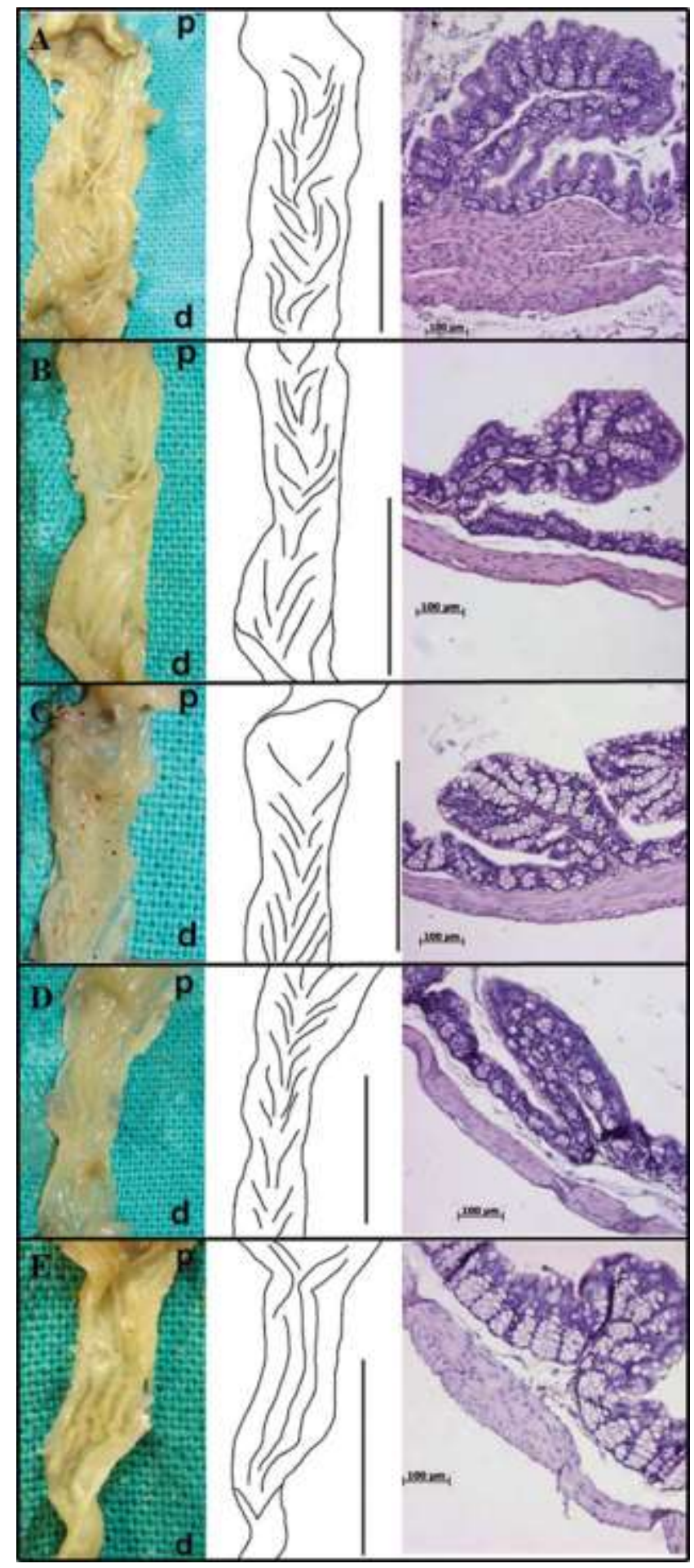

Fig. 5. The V shaped mucosal folds in the proximal colon of each species studied showing the macroscopic appearance, a line diagram and histology (H\&E stained). A) M. rex; B) M. libycus; C) A. dimidiatus; D) A. cahirinus; E) D. dasyurus. Vertical bars $=1 \mathrm{~cm}$. Bars on histology photographs $=100$ $\mu \mathrm{m} . \mathrm{p}=$ proximal. $\mathrm{d}=$ distal. 


\section{Measurements of the GIT}

The length and basal surface area of each GIT segment was expressed as a proportion of the total GIT length and basal surface area for each species (Table 2). Correlations between the absolute length and basal surface area of each segment compared with the body weights of the species were performed in order to compare the relative lengths and surface areas between the species.

Table 2. The mean proportions (\%) and Std. Dev ( \pm ) of the total GIT lengths, BSA, SEF and LSA of the anatomically distinct regions of the GITs.

\begin{tabular}{|c|c|c|c|c|c|}
\hline & M. rex & M. libycus & A. dimidiatus & A. cahirinus & D. dasyurus \\
\hline \multicolumn{6}{|l|}{$\begin{array}{l}\text { Proportional lengths } \\
(\%) \text { : }\end{array}$} \\
\hline Stomach & $9.90( \pm 1.5)^{\mathrm{c}}$ & $10.63( \pm 1.8)^{\mathrm{cb}}$ & $12.42( \pm 1.3)^{\mathrm{ab}}$ & $13.58( \pm 1.9)^{\mathrm{a}}$ & $8.46( \pm 1.9)^{\mathrm{c}}$ \\
\hline Small Intestine & $53.66( \pm 2.5)^{\mathrm{b}}$ & $44.77( \pm 4.7)^{\mathrm{d}}$ & $50.76( \pm 4.3)^{\mathrm{bc}}$ & $47.22( \pm 3.1)^{\mathrm{dc}}$ & $62.01( \pm 4.3)^{\mathrm{a}}$ \\
\hline Caecum & $12.84( \pm 2.1)^{\mathrm{ab}}$ & $15.21( \pm 4.2)^{\mathrm{a}}$ & $12.55( \pm 2.0)^{\mathrm{ab}}$ & $13.72( \pm 1.9)^{\mathrm{ab}}$ & $10.14( \pm 2.7)^{\mathrm{b}}$ \\
\hline Colon & $23.61( \pm 2.7)^{\mathrm{cb}}$ & $29.39( \pm 3.2)^{\mathrm{a}}$ & $24.28( \pm 4.5)^{\mathrm{cb}}$ & $25.49( \pm 2.8)^{\mathrm{ab}}$ & $19.40( \pm 0.4)^{\mathrm{c}}$ \\
\hline Caecum + Colon & $36.44( \pm 3.4)^{\mathrm{b}}$ & $44.60( \pm 5.0)^{\mathrm{a}}$ & $36.83( \pm 4.4)^{\mathrm{b}}$ & $39.20( \pm 3.6)^{\mathrm{ab}}$ & $29.54( \pm 2.8)^{\mathrm{c}}$ \\
\hline $\begin{array}{l}\text { Average total GIT } \\
\text { length }(\mathrm{mm})\end{array}$ & $850.00( \pm 105.8)^{\mathrm{a}}$ & $698.80( \pm 134.3)^{\mathrm{b}}$ & $509.40( \pm 76.0)^{\mathrm{c}}$ & $463.25( \pm 41.7)^{\mathrm{c}}$ & $542.67( \pm 182.4)^{\mathrm{bc}}$ \\
\hline \multicolumn{6}{|l|}{$\begin{array}{l}\text { Proportional BSA } \\
(\%)\end{array}$} \\
\hline Stomach & $25.19( \pm 4.7)^{\mathrm{ab}}$ & $24.75( \pm 6.8)^{\mathrm{ab}}$ & $27.37( \pm 6.0)^{\mathrm{ab}}$ & $31.47( \pm 6.7)^{\mathrm{a}}$ & $20.71( \pm 7.5)^{\mathrm{b}}$ \\
\hline Small Intestine & $38.02( \pm 2.4)^{\mathrm{b}}$ & $29.26( \pm 3.2)^{c}$ & $36.70( \pm 4.7)^{\mathrm{b}}$ & $35.51( \pm 2.3)^{\mathrm{bc}}$ & $51.64( \pm 10.3)^{\mathrm{a}}$ \\
\hline Caecum & $17.63( \pm 4.2)^{\mathrm{ab}}$ & $21.41( \pm 6.5)^{\mathrm{a}}$ & $15.61( \pm 4.4)^{\mathrm{ab}}$ & $14.20( \pm 1.4)^{\mathrm{b}}$ & $13.22( \pm 4.3)^{\mathrm{b}}$ \\
\hline Colon & $19.16( \pm 3.6)^{\mathrm{cb}}$ & $24.58( \pm 4.7)^{\mathrm{a}}$ & $20.32( \pm 3.6)^{\mathrm{ab}}$ & $18.83( \pm 3.8)^{\mathrm{cb}}$ & $14.42( \pm 1.8)^{\mathrm{c}}$ \\
\hline Caecum + Colon & $36.79( \pm 5.3)^{\mathrm{b}}$ & $45.99( \pm 8.8)^{\mathrm{a}}$ & $35.94( \pm 6.8)^{\mathrm{b}}$ & $33.02( \pm 5.1)^{\mathrm{b}}$ & $27.65( \pm 5.7)^{\mathrm{b}}$ \\
\hline $\begin{array}{l}\text { Average total GIT } \\
\text { BSA (mm) }\end{array}$ & $13890.6( \pm 1726)^{\mathrm{a}}$ & $11754.8( \pm 3911)^{\mathrm{a}}$ & $6189.2( \pm 1648)^{b}$ & $6028.0( \pm 825)^{\mathrm{b}}$ & $5851.3( \pm 2751)^{\mathrm{b}}$ \\
\hline \multicolumn{6}{|l|}{$\begin{array}{l}\text { Average Surface } \\
\text { enlargement factor: }\end{array}$} \\
\hline Stomach & $1.23( \pm 0.20)$ & $1.20( \pm 0.14)$ & $1.37( \pm 0.39)$ & $1.38( \pm 0.52)$ & $1.63( \pm 0.56)$ \\
\hline Small intestine & $6.06( \pm 0.75)^{\mathrm{a}}$ & $5.91( \pm 0.67)^{\mathrm{a}}$ & $5.74( \pm 1.26)^{\mathrm{a}}$ & $4.19( \pm 1.40)^{\mathrm{b}}$ & $4.91( \pm 0.37)^{\mathrm{ab}}$ \\
\hline Caecum & $2.33( \pm 0.72)$ & $2.25( \pm 0.99)$ & $2.17( \pm 0.48)$ & $2.23( \pm 0.73)$ & $2.84( \pm 0.61)$ \\
\hline Colon & $2.21( \pm 0.68)^{\mathrm{a}}$ & $1.93( \pm 0.47)^{\mathrm{ab}}$ & $1.77( \pm 0.31)^{\mathrm{ab}}$ & $1.22( \pm 0.15)^{b}$ & $1.73( \pm 0.76)^{\mathrm{ab}}$ \\
\hline \multicolumn{6}{|c|}{ Proportional LSA (\%): } \\
\hline Stomach & $9.00( \pm 1.4)^{\mathrm{b}}$ & $9.97( \pm 2.7)^{\mathrm{b}}$ & $11.58( \pm 2.3)^{\mathrm{b}}$ & $17.28( \pm 4.5)^{\mathrm{a}}$ & $9.46( \pm 3.5)^{\mathrm{b}}$ \\
\hline Small intestine & $67.15( \pm 2.8)^{\mathrm{ab}}$ & $58.25( \pm 3.5)^{\mathrm{b}}$ & $65.98( \pm 6.5)^{\mathrm{ab}}$ & $59.77( \pm 11.1)^{\mathrm{b}}$ & $71.86( \pm 11.5)^{\mathrm{a}}$ \\
\hline Caecum & $11.96( \pm 3.9)$ & $15.74( \pm 6.6)$ & $10.74( \pm 3.3)$ & $13.55( \pm 6.0)$ & $11.34( \pm 5.6)$ \\
\hline Colon & $11.88( \pm 2.2)^{\mathrm{ab}}$ & $16.04( \pm 5.1)^{\mathrm{a}}$ & $11.69( \pm 3.6)^{\mathrm{ab}}$ & $9.39( \pm 1.4)^{\mathrm{b}}$ & $7.34( \pm 4.0)^{\mathrm{b}}$ \\
\hline Caecum + Colon & $23.85( \pm 3.4)^{\mathrm{ab}}$ & $31.78( \pm 5.5)^{\mathrm{a}}$ & $22.43( \pm 6.5)^{\mathrm{b}}$ & $22.94( \pm 7.2)^{\mathrm{b}}$ & $18.68( \pm 8.3)^{b}$ \\
\hline $\begin{array}{l}\text { Average total GIT LSA } \\
(\mathrm{mm})\end{array}$ & $47697.2( \pm 9557)^{\mathrm{a}}$ & $\begin{array}{l}35900.7 \\
( \pm 17397)^{\mathrm{ab}}\end{array}$ & $\begin{array}{l}19484.7 \\
( \pm 5772)^{\mathrm{c}}\end{array}$ & $\begin{array}{l}14722.7 \\
( \pm 3308)^{\mathrm{c}}\end{array}$ & $\begin{array}{l}20652.5 \\
( \pm 10472)^{\mathrm{cb}}\end{array}$ \\
\hline
\end{tabular}

Statistical significant differences $(\mathrm{p}<0.05)$ are indicated by different superscript letters within a line. If no letters are indicated, no statistical significance was found. 


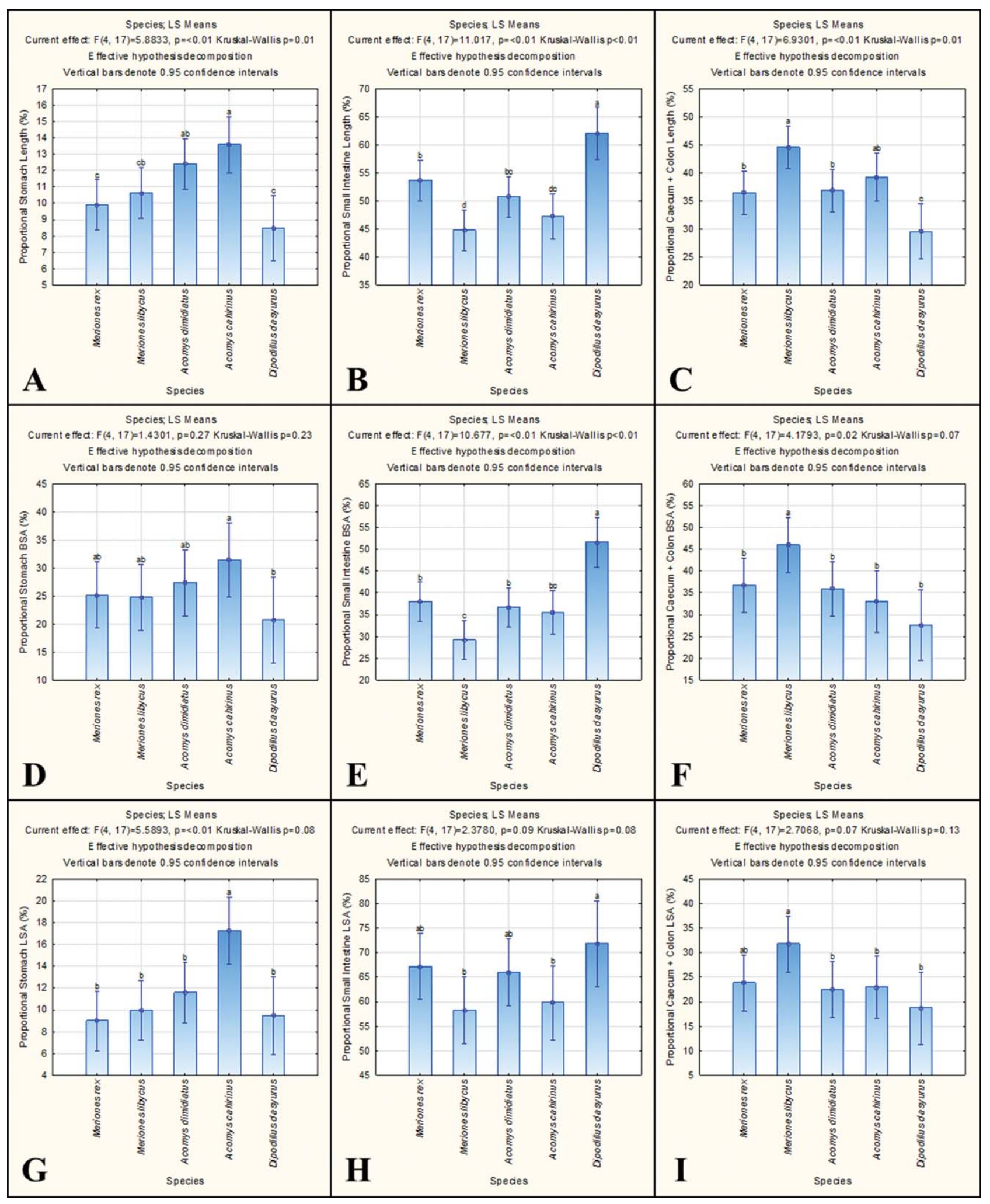

Fig. 6. Bar graphs of proportional lengths, BSA, and LSA of each segment of the GIT of Meriones rex, Meriones libycus, Acomys dimidiatus, Acomys cahirinus, a n d Dipodillus dasyurus. Statistical significance $(\mathrm{p}<0.05)$ is indicated with different letters of the alphabet. If the same letter/s is present above each of the species there are no significant differences. However, if the letter/s between the species is different from one another, it indicates statistical significance. The vertical lines on the bar graphs indicate a 95\% confi-dence interval. [Color figure can be viewed in the online issue, which is available at wileyonlinelibrary.com.] 
The proportional length and basal surface area of each segment of the GIT are illustrated in bar graphs (Fig. 6). Statistically significant differences were observed between species for the length and basal surface area of all the GIT segments. The longest proportional stomach is noted in A. cahirinus, while the shortest is observed in D. dasyurus, which had the longest proportional small intestine (Fig. 6A \& B). A correlation between the lengths and bodyweight of the species confirmed a relatively short stomach and relatively long small intestine for $D$. dasyurus compared with the other species (Fig. 7A \& B). M. libycus had the longest proportional combined caecum + colon of which the colon segment was significantly longer than all the species except in A. cahirinus (Table 2). This was confirmed in the correlation graph which showed the combined caecum and colon to be relatively long for $M$. libycus compared to the other species (Fig. 7C).

The stomach of A. cahirinus had the largest proportional basal surface area although it differed significantly only from D. dasyurus (Fig. 6D). The proportional small intestine basal surface area of $D$. dasyurus was significantly larger than all the other species (Fig. 6E). This was confirmed on the correlation graphs which also showed a relatively small stomach basal surface area in $D$ dasyurus. (Fig. 7D \& E). M. libycus had a significantly larger combined caecum + colon BSA than all the other species, however the caecum basal surface area by itself did not differ significantly from that of $M$. rex and $A$. dimidiatus (Table 2). The relatively large combined caecum + colon of M. libycus is confirmed in the correlation graph (Fig. 7F).

The surface enlargement factor that was used to calculate the luminal surface area showed a statistical significant difference between species in the the small intestine and 

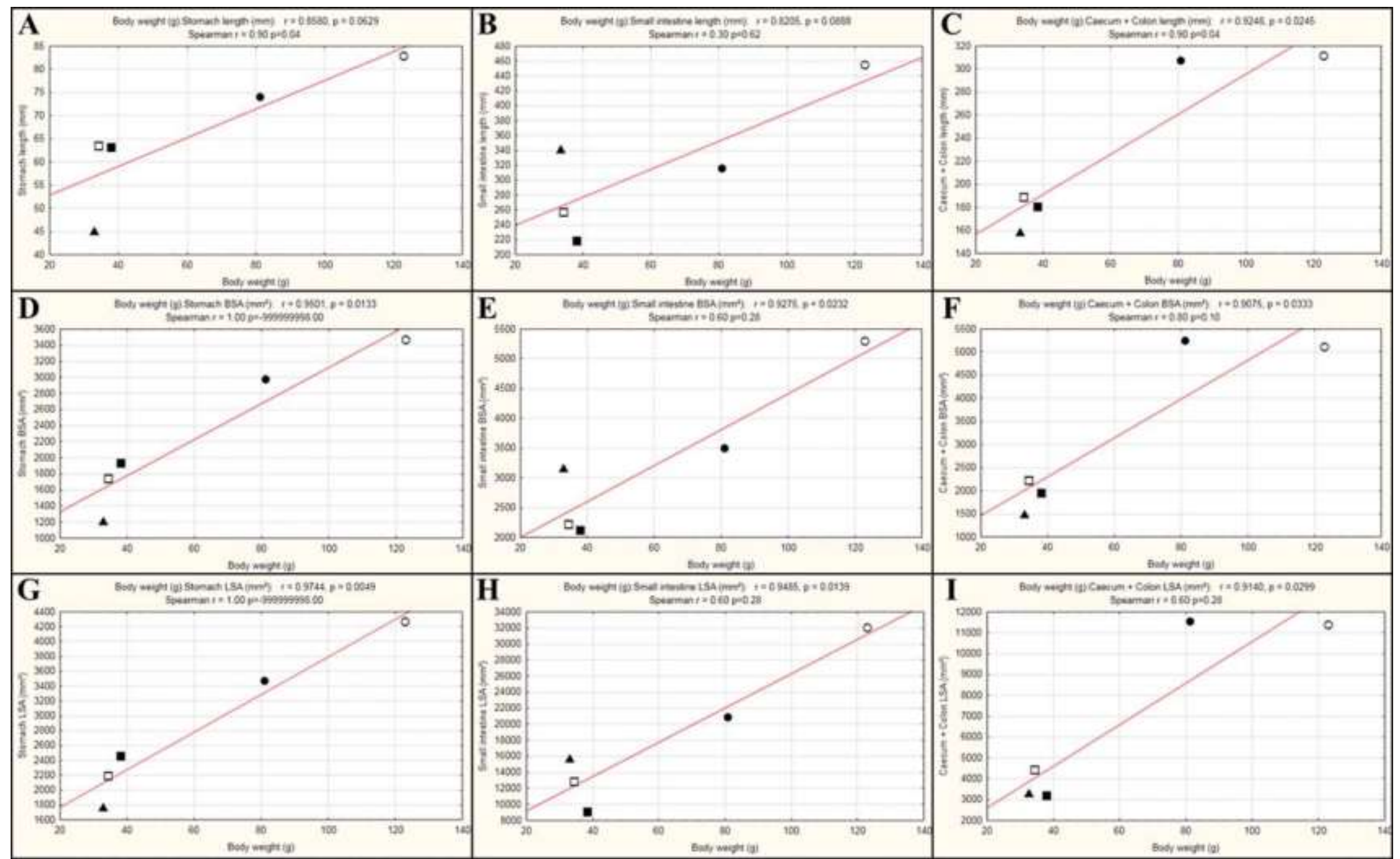

Fig 7. Correlations of the BSA of each region per species against the body weight of each species. Each marker on the scatterplot indicates a species. If a marker is further away from the line, it means the segment is relatively larger or smaller for that species compared to markers closer to the line. $\bigcirc$ M. rex, $\bullet$ M. libycus, $\square$ A. dimidiatus, cahirinus, $\mathbf{\Delta}$ D. dasyurus. 
colon. The average surface enlargement factor, as well as significant differences between species, is given in Table 2. For each segment of the GIT, the luminal surface area was calculated and given as a proportional luminal surface area to the total GIT luminal surface area (Table 2).

Results for the proportional luminal surface area as well as statistical significant differences between species are illustrated in bar graphs (Fig. 6). There was a statistically sinificant difference in the luminal surface area between species in all anatomical regions except the caecum. A. cahirinus had the largest proportional stomach luminal surface area and differed significantly from all the species (Fig. 6G). M. libycus had the largest proportional caecum + colon luminal surface area which differed significantly from all the speceis except $M$. rex (Fig. 6I). The correlation graphs confirmed a relatively large caecum + colon luminal surface area for M. libycus compared to the other species (Fig. 7I). D. dasyurus had the smallest proportional caecum + colon luminal surface area, however this may be due to the long small intestine of $D$. dasyurus, rather than a small caecum or colon, as observed in the correlations (Fig. 7H \& I).

\section{Stomach content analysis}

The stomach content analysis revealed an absence of any insect material. Examples of plant material and seeds identified are given in Fig. 8. Proportional content of plant material and seeds is given in Table 3 . 
Table 3: Proportion (\%) and standard deviations ( \pm ) of plant, seed and insect material in stomach contents

\begin{tabular}{llll}
\hline Species & Plant $(\%)$ & Seed $(\%)$ & Insect $(\%)$ \\
\hline M. rex & $83.27( \pm 13.21)$ & $16.73( \pm 13.21)$ & 0.00 \\
M. libycus & $85.89( \pm 9.71)$ & $14.11( \pm 9.71)$ & 0.00 \\
A. dimidiatus & $90.95( \pm 10.74)$ & $9.05( \pm 10.74)$ & 0.00 \\
*A. cahirinus & 95.29 & 4.71 & 0.00 \\
D. dasyurus & $92.67( \pm 9.04)$ & $7.33( \pm 9.04)$ & 0.00 \\
\hline
\end{tabular}

* Standard deviations were not included for A. cahirinus as only one specimen was available with stomach content.

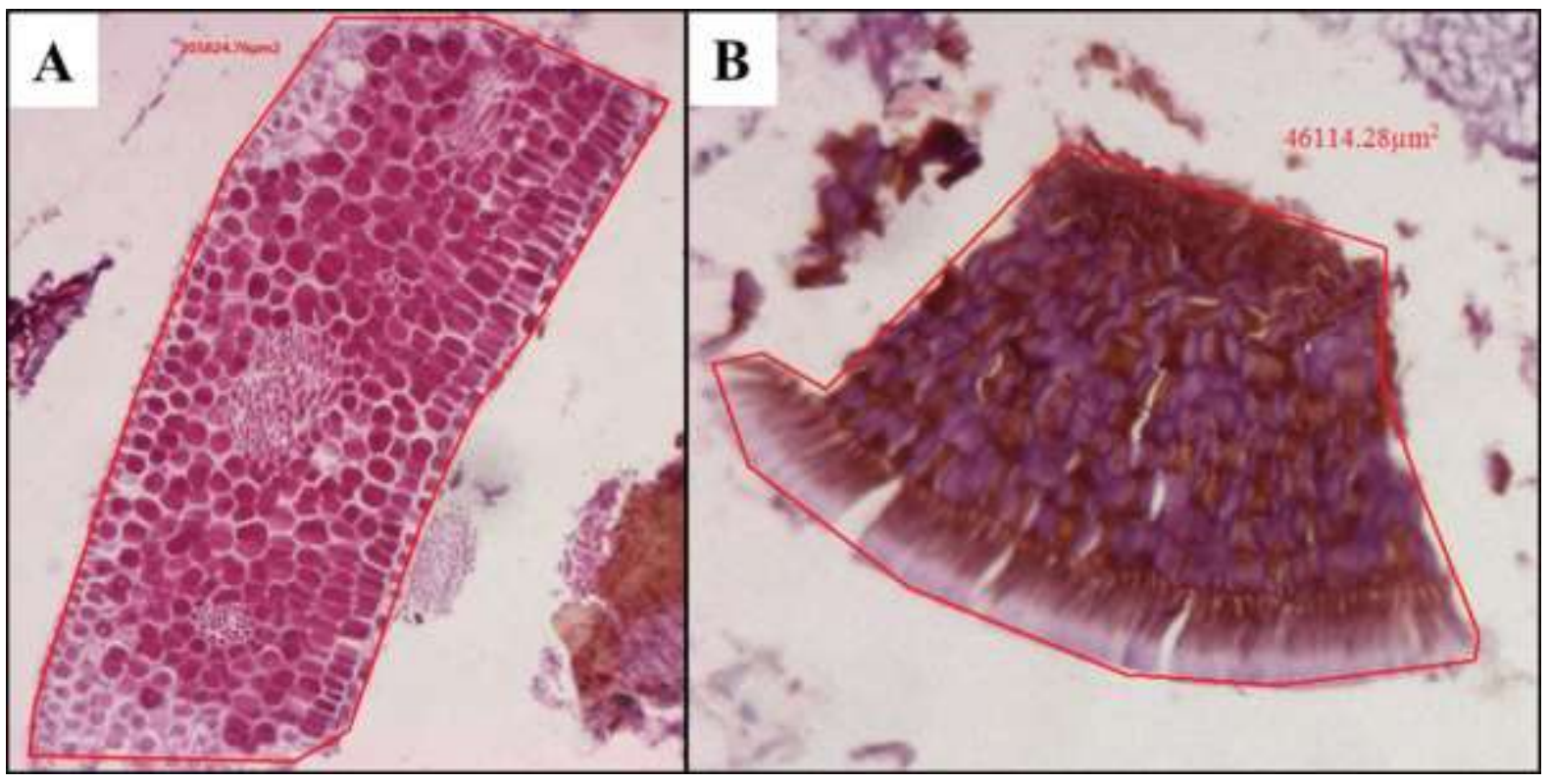

Fig. 8. Histological sections of the stomach content of $M$. rex. (H\&E stained). A) Example of plant material. 100X magnification; B) Example of seed material. 200X magnification.

\section{Discussion}

Certain predictions can be made about gut morphology and measurements relating to diet (Schieck and Millar, 1985) although differences in feeding habits alone do not always translate into differences in GIT morphology as life history, phylogeny and body size also play a role (Langer, 2002; Clauss et al., 2003; Stevens \& Hume, 1995). Of the animals studied here, $M$. rex, $M$. libycus and $D$. dasyurus have been reported to be herbivorous (Harrison and Bates, 1991; Nowak and Paradiso, 1983). The two Acomys 
species ingest mainly seeds, herbs and grasses but also show opportunistic omnivorous tendencies under certain circumstances such as ingesting small insects, dates and even mummified human flesh and bone marrow when available (Nowak and Paradiso, 1983). In the present study, the evaluation of undigested, recognizable stomach content revealed the presence of mostly plant material and small amounts of seeds in all species studied with an absence of insect material. However, as the animals in the present study were captured in the wild and their dietary habits were not observed over a period of time, the analysis of their stomach content only gives a brief snapshot into their actual dietary habits. It may mean that in the areas of capture for the present study, no insects were available.

In the present study, all species had unilocular hemiglandular stomachs as described in various rodent species (Carleton, 1973; Perrin and Curtis, 1980). Even though the fundus was curved or particularly pronounced in some species studied here, the angular incisure did not extend far beyond the opening of the oesophagus. There was therefore no evidence of compartmentalization of the stomach as described in old world Cricetinae (hamsters) by Carleton (1973). This single-chambered stomach with macroscopically visible differences between the stratified squamous epithelium and secretory gastric mucosa, separated by a ridge, was similar to that described in hamsters, voles, lemmings, and mice by Carleton (1973), in myomorph rodents (Perrin and Curtis, 1980), in the rat (Ghoshal and Bal, 1989), in vesper mice (Ellis et al., 1994) and in Acomys spinosissimus (Southern African Spiny Mouse) (Boonzaier et al., 2013). The separating ridge in rodents is referred to as a bordering fold (Carleton, 1973) or a limiting ridge (Robert, 1971) and in non-rodent mammals such as the horse, a similar elevated line is called the cuticular ridge or margo plicatus (Sisson, 1911). The non- 
glandular part of the stomach has been thought to have a function in food storage and is regarded as an adaptation to herbivory (Perrin and Curtis, 1980; Goshal and Bal, 1989).

In the present study, all caeca were similarly shaped with the ileocaecal and caeco-colic openings situated close together and the body of the caecum elongated and extending into a loose spiral towards the tip. This was in contrast to the broad sac-like ceacum observed in A. spinosissimus (Boonzaier et al., 2013). Taenia and haustra were not observed in any of the caeca or the colons of the present study as was the case in $A$. spinosissimus (Boonzaier et al., 2013). Taenia are usually associated with haustra which increase the storage volume of an organ and therefore cause retention or "damming up" of digesta. The latter is necessary in herbivorous species to allow time for fermentation (Langer and Takács, 2004). The lack of taenia is regarded as an undifferentiated form of adaptation to herbivory (Perrin and Curtis, 1980). The looped colons observed in the present study were consistent with that described in muroid rodents (Perrin and Curtis, 1980) and Hystricomorph rodents (Gorgas, 1967). Looping of the colon in herbivores have also been described in African mole-rats and postulated to be a way of "packaging" the colon into the abdominal cavity (Kotzé et al., 2006). The V shaped colonic folds observed in the Meriones and Acomys species in the present study were similar to those described in A. spinosissimus (Boonzaier et al., 2013) and almost all myomorph rodents according to Björnhag and Snipes (1999) and Hume (2002). These folds are postulated to retain food particles and therefore slow down digesta transit (Boonzaier et al., 2013). In addition to the oblique folds noted in the above mentioned species, $D$. dasyurus exhibited folds arranged in a loose longitudinally arranged spiral similar to that described in two insectivorous species (A. hottentotus, and C. cyanea) studied by Boonzaier et al. (2013). While coprophagy was never described in any of the 
species in the present study, it is possible that these folds may slow down the rate of digesta through the first part of the colon and may suggest a colonic separation mechanism (CSM). A CSM allows more digestible food particles to be retained in the caecum for longer while allowing course, less digestible food particles to be passed quickly (Hume, 2002). As the natural habitats of all the species in the present study are very arid regions, such a mechanism may benefit animals during times of food scarcity and low digestibility of forage.

Morphometric analysis of the length of different segments of the GIT only may not be truly representative of linking the morphology of GIT to dietary habits of a species (Perrin and Curtis, 1980). Despite this, intestinal length was used in comparative morphological studies on a wide variety of rodent GITs in the past (Gorgas, 1967; Perrin and Curtis, 1980). As in the present study, a more accurate assessment would be to take the relative surface areas of intestinal segments into account. The proportional lengths and basal surface areas has been used successfully in comparing the GIT of other species namely mole-rats (Kotzé et al., 2010) and three insectivorous mammals (Boonzaier et al., 2013). The present study not only took into account the basal surface area but also included the luminal surface area by using a surface enlargement factor similar to a study by Snipes and Kriete (1991) that compared intestinal measurements in 18 mammals. This approach therefore takes into account the surface enlargement due to villi, plicae circulares, and folds. While this approach has merit in terms of comparisons between species, the absolute values are not accurate as it does not take into account surface enlargement due to microvilli. It can therefore be used as an indication of the comparative luminal surface areas in the different species, as the same method was used in all the species studied here. All measurements were given as proportional 
measurements, namely as a percentage of the total GIT length, BSA, and LSA, respectively. This method was used to compensate for variations in body weights between species.

In the present study, by looking at only the proportional lengths of the different segments of the GIT, relatively long proportional small intestines and short proportional stomach lengths were observed. However, using the proportional basal surface areas a more even distribution between the GIT segments were observed due to the fact that the larger circumferences of the stomach and caecum compared to that of the small intestine and colon, were taken into account. For the proportional BSA the stomach was observed to be the second largest proportional segment instead of the smallest as observed with the lengths. The proportional LSA indicated a very large proportional small intestine due to the great increase in the LSA caused by villi.

In order to prevent misinterpretation of the proportional length and surface areas, correlations were done between the length or surface area of a GIT region and the body mass of the animals.

Correlations show that the Acomys species studied here have relatively long stomachs compared to the other species. The reason for this may be the large curving fundus observed in the Acomys stomach which was not observed in the A. spinosissimus (Boonzaier et al., 2013). Large variations were observed in the proportional small intestine lengths and surface areas. However, the small intestine is not a good indication of dietary adaptions in rodents (Stevens and Hume, 1995).

The largest proportional combined caecum and colon length and surface areas were observed in $M$. libycus which was confirmed with the correlations. The Meriones 
species consume mostly plant material and is in agreement with the literature where herbivorous species have been associated with a large caecum and long colon (Schieck and Millar, 1985; Stevens and Hume, 1995; Sakaguchi, 2003). D. dasyurus had a small proportional combined caecum and colon BSAs, LSAs, and lengths. As observed in the correlations, this is not due to the caecum and colon being small but rather due to the small intestine being relatively long in $D$. dasyurus compared to the other species.

The proportional caeca of all the species in the present study were relatively large compared with the other GIT segments and is consistent with what is found in small caecal fermenting omnivorous and herbivorous mammals (Hume, 2002). Due to the relative voluminous caeca in all the species in the present study, they may be classified as caecum fermenters where poor quality forages can be utilized which would otherwise not be possible due to their small body size (Cork et al., 1999). Small animals usually have a greater energy demand per unit body mass compared to larger animals (Björnhag, 1994). Therefore, smaller animals have to consume more food per unit body mass than larger animals consuming the same type of food. In the present study, the Acomys species had smaller body sizes than the A. spinosissimus studied by Boonzaier et al. (2013). Since these species live in desert regions with scarcity of water and good quality forage, the large caecum would be important for successful caecal fementation.

In conclusion, all the animals in the present study may be classified as mainly herbivorous. While the Acomys species consume insects in addition to plant material its GIT morphology does not resemble that of typical insectivores namely a simple glandular stomach and the lack of a caecum as described by Boonzaier et al (2013). It may be that the dietary differences between the species studied here are too subtle to 
cause major differences in the GIT morphology. With phylogenetic grouping of the animals in terms of the subfamily, one would have expected the Meriones and $D$. dasyurus, which is of a different subfamily than the Acomys species, to have similar gut morphology. This was however not supported by the GIT measurements. However, grouping according to the family Muridae, many similarities were apparent such as the hemiglandular stomachs and relatively large caeca in all species studied here. Therefore, it could be concluded that phylogeny plays an important role in determining GIT morphology while diet plays a subordinate role in the structure of the GIT of the desert dwelling rodents in the present study.

\section{Acknowledgements}

We would like to acknowledge the Harry Crossley Foundation and Deanship of Scientific Research at the King Saud University (research group project No. RGP_VPP_020) for funding the work. Authors would like to thank HH Prince Bandar bin Saud bin Mohammed Al-Saud, President of Saudi Wildlife Authority, for permission to trap the animals in the Riyadh Protected Area and National Wildlife Research Centre in Taif. Thanks to Reggie Williams for help with histology.

\section{References}

Alagaili AN, Mohammed OB, Bennett NC, Oosthuizen MK. 2012a. Lights out, let's move about: locomotory activity patterns of Wagner's gerbil from the desert of Saudi Arabia. African Zoology, 47:195-202. 
Alagaili AN, Mohammed OB, Bennett NC Oosthuizen MK. 2012b. A tale of two jirds: The locomotory activity patterns of the King jird (Meriones rex) and Lybian jird (Meriones lybicus) from Saudi Arabia. Journal of Arid Environments, 88:102-112.

Alagaili AN, Mohammed OB, Bennett NC, Oosthuizen MK. 2013. Down in the Wadi: the locomotory activity rhythm of the Arabian spiny mouse, Acomys dimidiatus from the Arabian Peninsula. Journal of Arid Environments, In Press.

Björnhag G. 1994. Adaptations in the large intestine allowing small animals to eat fibrous foods. In: Chivers D, Langer P, editors. The digestive system in mammals: food, form and function. Cambridge: Cambridge University press. p 287-309.

Björnhag G, Snipes RL. 1999. Colonic Seperation Mechanism in Lagomorph and Rodent Species -a Comparison. Zoologie Reihe 75:275-281.

Boonzaier J, Van der Merwe EL, Bennett NC, Kotzé SH. 2013. Comparative Gastrointestinal Morphology of Three Small Mammalian Insectivores: Acomys spinosissimus (Rodentia), Crocidura cyanea (Eulipotyphla), and Amblysomus hottentotus (Afrosoricida). Journal of Morphology 274:615-626.

Carleton MD. 1973. A Survey of Gross Stomach Morphology in New World Cricetinae (Rodentia, Muroidea), with Comments on Functional Interpretations. Miscellaneous Publications. Museum of Zoology. University of Michigan 146:1-43.

Clauss M, Frey R, Kiefer B, Lechner-Doll M, Loehlein W, Polster C, Rössner GE, Streich WJ. 2003. The maximum attainable body size of herbivorous mammals: morphophysiological constraints on foregut, and adaptations of hindgut fermenters. Journal of Morphology 259:308-315 
Cork SJ, Hume ID, Faichney GJ. 1999. Digestive Strategies of Nonruminant Herbivores: The Role of the Hindgut. In: Jung HJG, Fahey GC, editors. Nutritional Ecology of Herbivores. Illinois: American Society of Animal Science. p 210-260.

Ellis BA, Mills JN, Kennedy EJT, Maiztegui JI, Childs E. 1994. The relationship among diet, alimentary tract morphology, and life history for five species of rodents from the central Argentine pampa. Acta Theriol 39:345-355.

Ghoshal NG, Bal HS. 1989. Comparative morphology of the stomach of some laboratory mammals. Laboratory Animals 23:21-29.

Gorgas M. 1967. Vergleichend-anatomische Untersuchungen am Magen-Darm-Kanal der Scuiromorpha, Hystricomorpha und Caviomorpha (Rodentia). Zeitschrift für wissenschaftliche Zoologie 175:237-404.

Harrison DL, Bates PJJ. 1991. The Mammals of Arabia ( $2^{\text {nd }}$ edition). England: Harrison Zoological Museum Publication.

Hume ID. 2002. Digestice strategies of mammals. Acta Zoologica Sinica 48:1-19.

Kotzé SH, Van der Merwe EL, O’Riain MJ. 2006. The Topography and Gross Anatomy of the Gastrointestinal Tract of the Cape Dune Mole-rat (Bathyergus suillus). Anat. Histol. Embryol. 35:259-264.

Kotzé SH, Van Der Merwe EL, Bennett NC, O’Riain MJ. 2010. The Comparative Anatomy of the Abdominal Gastrointestinal Tract of Six Species of African Mole-Rats (Rodentia, Bathyergidae). Journal of Morphology 271:50-60. 
Langer P. 2002. The digestive tract and life history of small mammals. Mammal Review 32(2):107-131.

Langer P, Takács A. 2004. Why Are Taeniae, Haustra, and Semilunar Folds Differentiated in the Gastrointestinal Tract of Mammals, Including Man? Journal of Morphology 259:308-315.

Nowak RM, Paradiso JL. 1983. Walker's Mammals of the World. Baltimore, Maryland: The Johns Hopkins University Press.

Perrin M, Curtis B. 1980. Comparative morphology of the digestive system of 19 species of Southern African myomorph rodents in relation to diet and evolution. South African Journal of Zoology 15(1):22-33.

Robert A. 1971. Proposed terminology for the anatomy of the rat stomach. Gastroenterology 60:344-345.

Sakaguchi E. 2003. Digestive strategies of small hindgut fermenters. Animal Science Journal 74:327-337.

Sanborn CC, Hoogstraal H. 1953. Some Mammals of Yemen and Their Ectoparasites. Fieldiana: Zoology 34:229-252.

Scantlebury M, Shanas U, Afik D, Haim A. 2005. Comparative seasonal acclimatization of food and energy consumption in adjacent populations of common spiny mice (Acomys cahirinus). J. Zool 267:323-328.

Schieck JO, Millar JS. 1985. Alimentary tract measurements as indicators of diets of small mammals. Mammalia 49(1):93-104. 
Sisson S. 1911. A Text-Book of Veterinary Anatomy. Philadelphia and London: W. B. Saunders Company.

Snipes LR, Kriete A. 1991. Quantitative investigation of the area and volume in different compartments of the intestine of 18 mammalian species. Zeitschrift für Säugetierkunde 56:225-244.

Stevens CE, Hume ID. 1995. Comparative Physiology of the Vertebrate Digestive System (2nd ed.). Cambridge: Cambridge University Press.

Varty N. 1990. Ecology of the small mammals in the riverine forests of the Jubba Valley, Southern Somalia. Journal of Tropical Ecology 6:179-189.

Vesey-Fitzgerald D. 1966. Notes on Some Rodents from Saudi Arabia and Kuwait. Journal Bombai Natural Hist. Society 51:424-428.

Wilson D, Reeder D. 2005. Mammal Species of the World. A Taxonomic and Geographic Reference, 3rd ed. Baltimore, MD: Johns Hopkins University Press. Available at: www.bucknell.edu/msw3/. Accessed on 2 August 2013. 